\title{
A Study of Correlation between Crack Initiation during Dynamic Wear Process and Fatigue Crack Growth of Reinforced Rubber Materials
}

\author{
Eric Euchler, ${ }^{1}$ Ondrej Kratina, ${ }^{2,3}$ Radek Stoček, ${ }^{3,4}$ and Michael Gehde ${ }^{1}$ \\ ${ }^{1}$ Chemnitz University of Technology, 09107 Chemnitz, Germany \\ ${ }^{2}$ Department of Polymer Engineering, Faculty of Technology, Tomas Bata University Zlín, 76001 Zlín, Czech Republic \\ ${ }^{3}$ Centre of Polymer Systems, University Institute, Tomas Bata University in Zlín, 76001 Zlín, Czech Republic \\ ${ }^{4}$ PRL Polymer Research Lab., s.r.o., 76001 Zlín, Czech Republic
}

Correspondence should be addressed to Eric Euchler; eric.euchler@mb.tu-chemnitz.de

Received 1 August 2014; Accepted 12 January 2015

Academic Editor: Matthias Scherge

This Conference Paper is based on a presentation given by Eric Euchler at "European Symposium on Friction, Wear, and Wear Protection" held from 6 May 2014 to 8 May 2014 in Karlsruhe, Germany.

Copyright (C) 2015 Eric Euchler et al. This is an open access article distributed under the Creative Commons Attribution License, which permits unrestricted use, distribution, and reproduction in any medium, provided the original work is properly cited.

\begin{abstract}
The aim of this study is concentrated on the experimental investigation of crack initiation during dynamic wear process and its correlation with fatigue crack growth of reinforced rubber materials. The analyzed rubber compounds suitable for applications such as treads for truck tires were based on natural rubber (NR) and polybutadiene rubber (BR). The dynamic wear behavior has been studied using an own developed testing equipment based on gravimetric determination of mass loss of test specimen. Fatigue crack growth (FCG) analysis was performed under pulse loading in accordance with real dynamic loading conditions of rolling tires using the Tear Analyser (TA). We show the crack initiation process during dynamic wear with respect to different impact energies and correlate the liability of crack initiation with FCG data at given tearing energy as a function of the rubber compositions. We demonstrate the higher crack initiation resistance of rubber blends with increased content of BR, while a predominant influence of NR improves the resistance against crack propagation especially at higher strain levels due to strain induced crystallization.
\end{abstract}

\section{Introduction}

Reinforced rubber materials are found in many applications, such as conveyor belts, hoses, seals, and certainly tires. We focused our study on rubber materials which are suitable for tire tread applications to show the importance of experimental characterization based on dynamic wear for improving the service life time of tires.

In practice, rubber parts like tire treads are cyclically loaded and exposed to the dynamic impact caused by the roughness of the road surface at the region of the tire footprint. In Figure 1 the loading process on tire treads is shown schematically. The dynamic load causes deformations of the affected zone, which are applied in milliseconds. Succeeding, the deformations relax until the next contact (impact from specific asperity, revolution of tire, etc.) occurs.
Due to the viscoelastic behavior of rubber materials the deformation energy is not completely reversible but contains a dissipative part, meaning the acting deformations lead to regions of energy dissipations, which are significantly high in the smallest contact area (see Figure 1). Thus, affecting tire tread depends on the roughness and the asperity of the of road surface, whereas hard terrain represents the highest asperity in the practice. The tread of truck tires used in a hard terrain is exposed to the most critical state, because of the heavy load which is commonly applied. Therefore we concentrated our experimental characterization on rubber material used for tread of truck tires. Usually, typical rubber compounds for treads of truck tires are based on NR/BR-blends (NR = natural rubber/BR = butadiene rubber) filled with carbon black or silica [1]. 


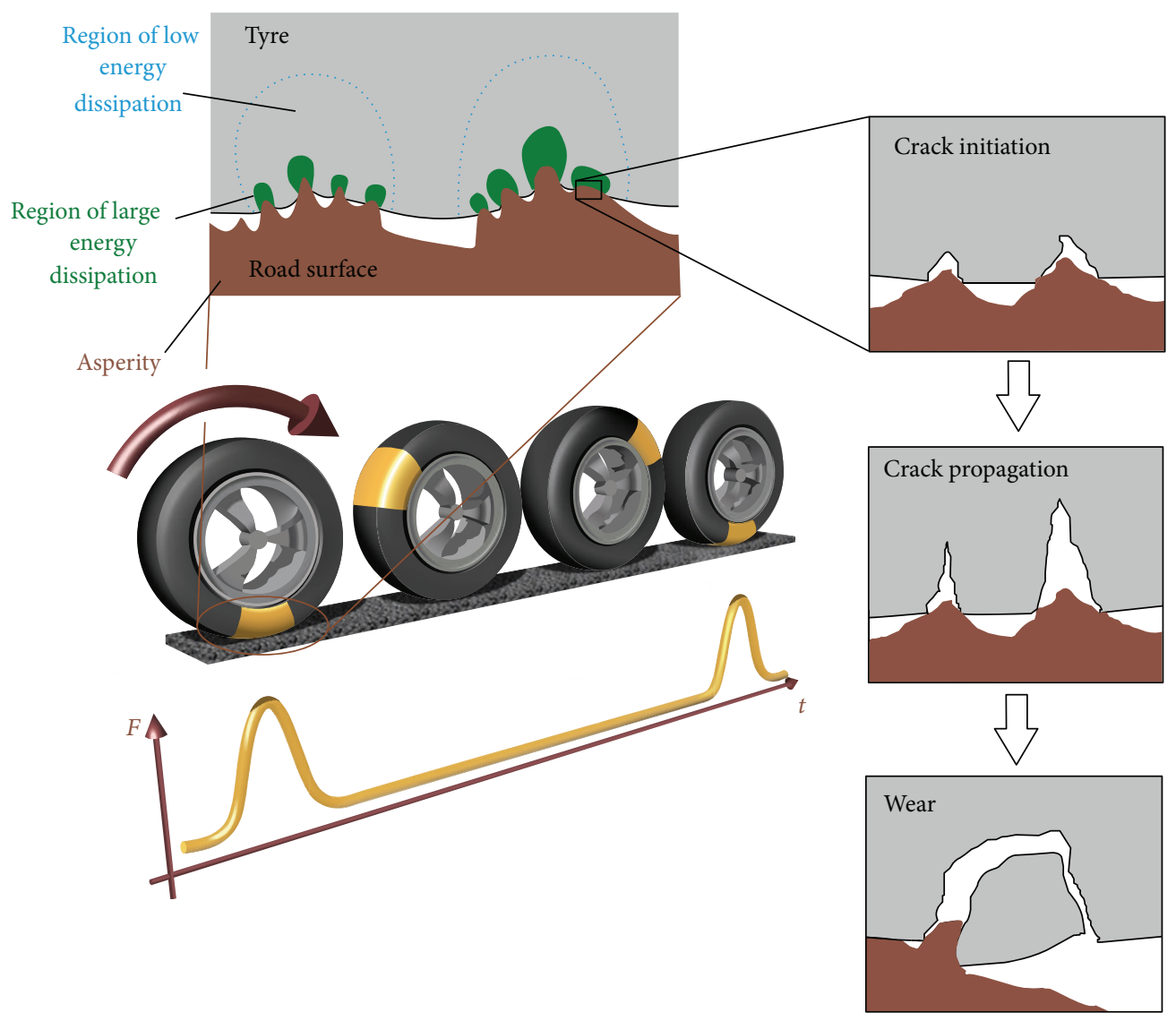

FIGURE 1: Visualization of tire tread loading and failure process.

The failure behavior of tire treads is caused particularly by crack initiation and its continuous propagation. Millions of fatigue cycles lead to substantial wear of the tread, which could expire in catastrophic failure. Visualization of real loading conditions and the principle of dynamic wear process are shown in Figure 1 with the example of a tire tread.

In general, highly dynamic conditions lead to wear induced by fatigue and abrasion, due to frictional sliding, which have effects on the degradation of the mechanical performance of the global rubber network characterized, for example, by a cyclic breakdown of polymer-filler-network clusters. Furthermore the wear process leads to crack initiation and its propagation [2]. The fracture process starts due to microcrack initiation, whereby the reason for its mechanical initiation is a foreign object (specific asperity of the road surface, stones, etc.), which has a considerable higher E-modulus in comparison with the rubber surface. Commonly, dynamical impacts on the tire tread occur in the normal direction to the tire tread surface and simultaneously influence the stress at the contact zone where frictional sliding between rubber and road surface occurs [3]. Accruing microcracks can be initiated in the impact or in the sliding phase, whereby both cases are characterized by unreproducible high dynamic changes of stress and energy dissipation in the rubber bulk between strained and relaxed conditions.
TABLE 1: List of used rubber blends.

\begin{tabular}{lccc}
\hline Rubber type & \multicolumn{3}{c}{ Rubber blends } \\
& A & B & C \\
\hline Natural rubber (NR) & $85 \mathrm{phr}$ & $80 \mathrm{phr}$ & $75 \mathrm{phr}$ \\
Butadiene rubber (BR) & $15 \mathrm{phr}$ & $20 \mathrm{phr}$ & $25 \mathrm{phr}$ \\
\hline
\end{tabular}

\section{Materials and Experimental Details}

Three distinct rubber compounds based on NR and BR were filled with $55 \mathrm{phr}$ of standard carbon black N220. The rubber compounds differ in the NR/BR-ratio (see Table 1). Additional typical curatives were added as well as a sulfuraccelerator-system. The rubber compounds were prepared by Mitas a.s. (Czech Republic). Rheometric properties were determined referring to DIN 53529. Vulcanization of the samples was performed in a heat press at $160^{\circ} \mathrm{C}$ and $10 \mathrm{MPa}$ according to the determined rheometric properties.

The determined testing parameters for characterization of wear behaviour of applied tire tread rubber materials refer to known loading conditions occurring during operation of tires. In Figure 2 and in Table 2 constructional details of a typical truck tire (315/70 R 22.5) and typical deformation values at static load are illustrated and summarized. With respect to the loading conditions occurring in practice 
TABLE 2: Constructional details and real operation conditions of a typical truck tire (315/70 R 22.5) [4].

\begin{tabular}{lccccccc}
\hline & \multicolumn{6}{c}{ Constructional details and real operation conditions } \\
$D[\mathrm{~mm}]$ & $r[\mathrm{~mm}]$ & $h[\mathrm{~mm}]$ & $w[\mathrm{~mm}]$ & Deflection $^{*}[\mathrm{~mm}]$ & Deflection $^{* *}[\%]$ & Driving speed $[\mathrm{km} / \mathrm{h}]$ & Frequency $[\mathrm{Hz}]$ \\
\hline 1014 & 468 & 220.5 & 315 & 39 & 17.7 & $10-100$ & $0.9-8.7$ \\
\hline
\end{tabular}

${ }^{*}$ Deflection: $f=(D / 2-r)$.

** Deflection: $f^{\prime}=(f / h)$.

TABLE 3: Determined testing constraints with respect to real loading conditions.

\begin{tabular}{lccc}
\hline \multicolumn{3}{c}{ Testing conditions } & \\
$\begin{array}{l}\text { Frequency } \\
{[\mathrm{Hz}]}\end{array}$ & $\begin{array}{c}\text { Deformation } \\
\text { amplitude }[\%]\end{array}$ & $\begin{array}{c}\text { Pulse } \\
\text { width }[\mathrm{ms}]\end{array}$ & $\begin{array}{c}\text { Deformation } \\
\text { speed }[\mathrm{mm} / \mathrm{s}]\end{array}$ \\
\hline 1 & $13-30$ & 100 & $39-90$ \\
\hline
\end{tabular}

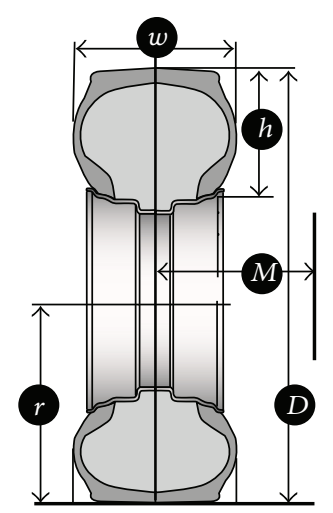

Figure 2: Constructional details of a typical truck tire under static load [4].

(Table 2) the testing constraints of wear tests were defined as shown in Table 3.

\section{Dynamic Wear Analysis}

In 1982 Beatty and Miksch [5] both developed laboratory equipment and established a measuring methodology for the characterization of abrasion in accordance with the practical use of rubber products with respect to the dynamic loading conditions. This research publication was the bases for the design of new testing equipment by Manas et al. [6] firstly enabling the variation of testing parameters. This procedure is based on a simulation of impacted rolling test specimens and Beatty and Miksch termed this dynamic wear process the Chip and Cut (CC) effect.

CC experiments were carried out using an own developed prototype of a CC analyzer (schematically shown in Figure 3) based on the measuring principle of Beatty and Miksch [5]. The force $F_{L}$ is induced by a static load with variable weight. A multiphase motor leads the actuating arm (1) to swing from the bottom to the upper position and reverse. Due to the driving of the multiphase motor the oscillating arm (2) is held in the upper position at the defined given time. Thus a loading condition according to the real tire rolling could firstly be simulated. The oscillating arm (2) with the ceramic cutting

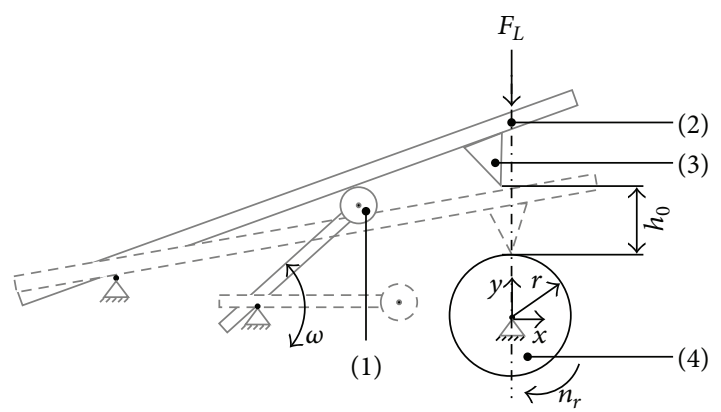

Figure 3: Principle of the Chip and Cut Tester; (1) actuating arm and multiphase motor, (2) oscillating arm, (3) ceramic cutting tool, and (4) test specimen.

tool (3) (type: TNGN 220616, made by CORUN, Serbia) falls due to free fall and impacts the revolving rubber test specimen (4).

The cutting process is carried out in the range of milliseconds. The process is repeated in a defined frequency on the basis of real loading conditions. The total impact energy $\left(E_{\text {impact }}\right)$ consists of a summation of the components in normal $\left(E_{\text {normal }}\right)$ and tangential $\left(E_{\text {tangential }}\right)$ direction:

$$
E_{\text {impact }}=E_{\text {normal }}+E_{\text {tangential }} \text {. }
$$

In this study, cylindrical test specimens with radius $27.5 \mathrm{~mm}$ and thickness $13.0 \mathrm{~mm}$ were analyzed over a time period of $24 \mathrm{~h}$. The loading condition is defined on the basis of pulse width $100 \mathrm{~ms}$, frequency $1 \mathrm{~Hz}$, and a variation of rotation speed $n_{r}$ between 17 and $31 \mathrm{rev} \cdot \mathrm{min}^{-1}$. Mainly, the value of rotation speed influences the energy component in tangential direction. The range of rotation speed was calculated considering the assumption deformation speeds at the rubber surface at CC and FCG have to be equal or rather the time required for the deflection of typical values of tire treads in practice has to be equal. The unique normal load $\left(F_{L}=14.5 \mathrm{~N}\right)$ was applied directly on the shifting arm using weights. The distance $h_{0}$ was set at $20.0 \mathrm{~mm}$.

The test specimens were weighed before and after the CC experiment. During the experiment particles have been released from the rubber test specimens, which need to be cleaned by brushing.

\section{Fatigue Crack Growth Analysis}

FCG measurements were carried out using a Tear Analyser (Coesfeld Materialtest GmbH \& Co. KG) under applied pulse loading with respect to real tire loading conditions (see Figure 1). The frequency for the pulse loading was set at $1 \mathrm{~Hz}$ 
and pulse width at $100 \mathrm{~ms}$. The strain amplitude was varied between $13 \%$ and $30 \%$ which is a typical range for tire tread deflection during operation (see Table 3). The analysis was performed at $23^{\circ} \mathrm{C}$ temperature and a humidity of $50 \%$. In this study standard pure shear test specimens with the geometry ratio $L_{0}$ (length) $/ Q$ (width) $=1: 8$ were used [7]. Two double notched and one unnotched pure shear test specimens were analyzed simultaneously. Each of the notched pure shear test specimens were notched by a length of $a_{0}=25 \mathrm{~mm}$ on both sides using the definition of minimal notch length $a_{0}$ min depending on geometry ratio $L_{0} / Q$ [7].

Characterization of crack propagation in reinforced rubber materials is based on a global energy balance in which the tearing energy was introduced by Rivlin and Thomas [8] as the energy required for the creation of a unit area of new crack surface. Considering the special case of crack propagation in a pure shear test specimen without crack deflection, the tearing energy $T$ can be calculated with

$$
T=w \cdot L_{0},
$$

where $w$ is the strain-energy density, which is determined from measurement of the tensile stress-strain curve of the unnotched test specimen, and $L_{0}$ is the length of test specimen in the unstrained state.

The crack growth rate per cycle $d a / d n$ is a function of the tearing energy T. Paris and Erdogan [9] described this relationship with the law of force:

$$
\frac{d a}{d n}=B \cdot T^{m}
$$

where $a$ is the crack length, $n$ is the number of cycles, and $B$ and $m$ are material dependent parameters (e.g., Gent et al. $[10])$.

\section{Results and Discussion}

In Figure 4 it is shown that the BR content has a significant influence on the wear resistance of given rubber compounds. Increasing $\mathrm{BR}$ content is the reason for a higher wear resistance, represented by a lower mass loss. Higher amounts of BR lead to higher mass loss rates (higher slopes) with increasing revolution speed of test specimen. Grosch [11] observed similar wear behavior of NR/BR-blends, whereas he studied the steady state behaviors. The established higher crack initiation resistance of BR against NR was demonstrated in further works (e.g., $[10,12])$ as well.

In Figure 5, the influence of the rubber composition on the FCG rate under pulse loading conditions becomes apparent. Partially, the FCG rate changes with given tearing energy depending on the amount of $\mathrm{BR}$ in compounds. Compounds with higher BR content $(B, C)$ show a transition point at $25 \%$ strain. At strain levels below this transition point, crack growth rate resistance of the tread compounds with higher BR content (B, C) increases (slight slopes). Above the transition point the compound with predominant influence of NR improves the resistance against crack propagation due to strain induced crystallization in NR at large strains, while higher BR contents in tread compounds lead to increasing

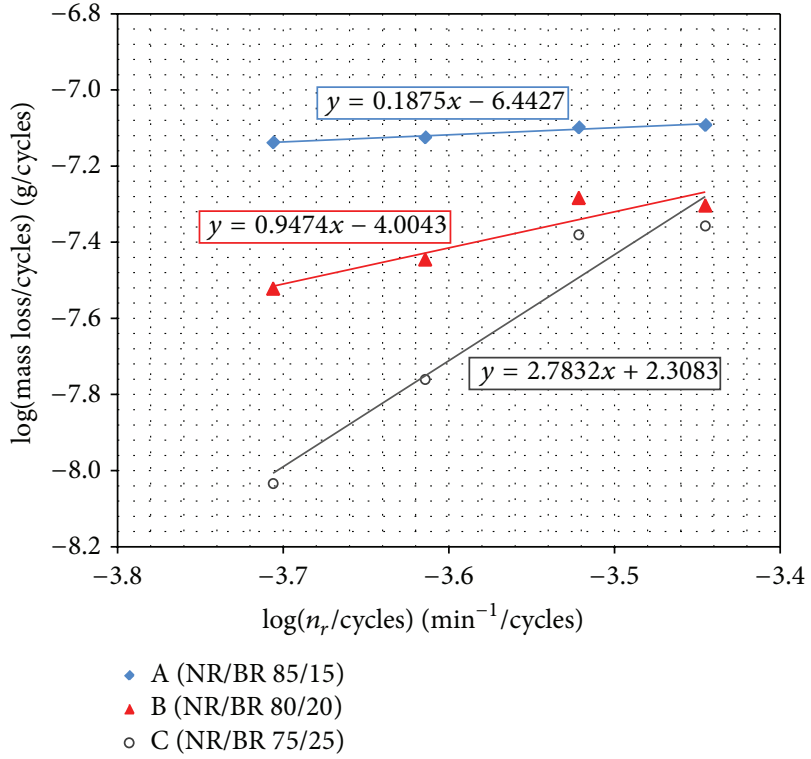

FIGURE 4: Double logarithmic plot of mass loss as function of revolutions.

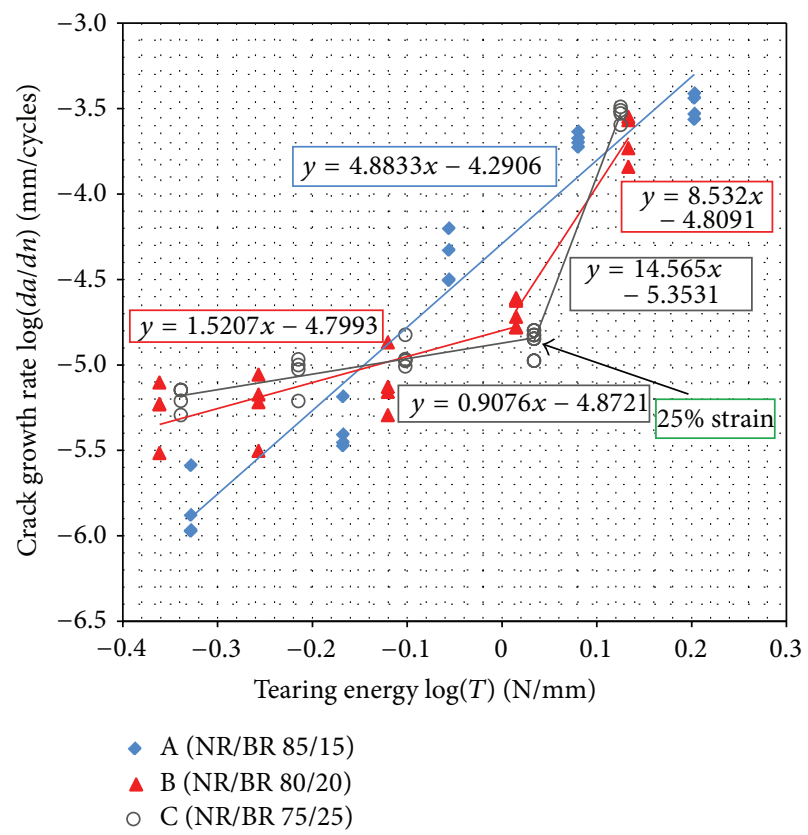

FIGURE 5: FCG with variation of tearing energy.

FCG rates. A prior study [12] showed similar results concerning the existence of a transition point in FCG rates for NR/BRcompounds depending on strain level as well as BR content.

Generally, the measurement principles of both methods are distinctly divergent. On the one hand the Tear Analyser, as standard testing equipment for FCG data, provides data describing the crack propagation behavior of rubber. In this case the crack propagation of an already existing notch is generated by certain strain amplitudes. The validity of FCG data at real pulsed loading conditions has been proved in 
many publications to have a predictive value $[7,13,14]$. On the other hand CC data are provided by a chipping and cutting test system occupying an unnotched test specimen, meaning apart from the singularity of the crack propagation the crucial crack initiation process is investigated hereby as well. Certainly, the crack initiation mechanism has to be distinguished from the crack propagation process, but one has to consider that CC data provide an overlay of crack initiating and crack propagating rates. The crack initiation process is characterized by unreproducible high dynamic changes of stress and energy dissipation. Because of the fact that the single crack initiation mechanisms can hardly be separated, currently the evaluated CC data have only qualitative validity. However, a correlation of crack initiation mechanisms during dynamic wear processes and crack growth behavior is identifiable considering the rubber type of applied rubber compounds. Depending on the differences in molecular structure between $\mathrm{NR}\left(\mathrm{C}_{5} \mathrm{H}_{8}\right)$ and $\mathrm{BR}\left(\mathrm{C}_{4} \mathrm{H}_{6}\right)$ distinctions of mechanical properties become apparent. The achieved results illustrate the higher crack initiation resistance of BR with data of CC measurements and the higher crack propagation resistance of NR due to the results of FCG analysis. Thus, the correlation of determined data supports the well-known contrasting trends of both material properties regarding crack initiation and crack propagation resistances [12]. Thereby the broad range of deformation values contains different loading condition scenarios: lower deformation values characterize loading conditions of tire treads on surfaces with slight roughness (e.g., on road) and higher deformation values describe the loading conditions at surfaces with high asperity (e.g., pothole on roads; off road). Conclusively, the investigations on the dynamic wear process of truck tire treads provide valuable information about the mechanical performance of the treads under simulation of loading conditions nearby the reality occurring while driving in hard terrain. Consequently the service life time of truck tires can be improved considering the data of CC and FCG as well.

\section{Conclusion}

In this work we investigated the influence of the rubber base on the dynamic wear process of three different rubber compounds typical for tire treads. The dynamic wear process has been studied using an own developed Chip and Cut Tester and a standard Tear Analyser. The two testing methods are suitable for investigations of the fracture process of rubber materials under real loading conditions. The unconventional $\mathrm{CC}$ test enables qualitative assumptions on the dynamic wear process involving crack initiation and propagation mechanisms, while the predictive value of FCG data is proven. Similar trends regarding wear resistance have been observed for both measuring systems with respect to the used materials.

The study gives a set of truck tread compound ratings concerning dynamic wear resistance under loading conditions nearby the reality. We demonstrated that the FCG resistance as well as the crack initiation behavior depends on the NR/BR-ratio. BR improves crack initiation resistance of rubber products, while NR increases the FCG resistance especially at high periodic loading conditions. Hence, the strain level is an important criterion for the selection of tread compounds concerning dynamic wear behavior in practice.

\section{Conflict of Interests}

The authors declare that there is no conflict of interests regarding the publication of this paper.

\section{Acknowledgments}

This paper was written with the support of the Operational Programme "Education for Competitiveness" cofunded by the European Social Fund (ESF) and the national budget of the Czech Republic, project: Advanced Theoretical and Experimental Studies of Polymer Systems (reg. no. CZ.1.07/2.3.00/20.0104). This paper was written with the support of the Operational Programme "Research and Development for Innovations" cofunded by the European Regional Development Fund (ERDF) and the national budget of the Czech Republic, project: Centre of Polymer Systems (reg. no. CZ.1.05/2.1.00/03.0111). The authors thank the Managing Committee of Mitas a.s. (Czech Republic) for providing of rubber compounds.

\section{References}

[1] G. Heinrich, M. Klüppel, and T. A. Vilgis, "Reinforcement of elastomers," Current Opinion in Solid State and Materials Science, vol. 6, no. 3, pp. 195-203, 2002.

[2] H. Lorenz and M. Klüppel, "Microstructure-based modelling of arbitrary deformation histories of filler-reinforced elastomers," Journal of the Mechanics and Physics of Solids, vol. 60, no. 11, pp. 1842-1861, 2012.

[3] Y. Fukahori, H. Liang, and J. J. C. Busfield, "Criteria for crack initiation during rubber abrasion," Wear, vol. 265, no. 3-4, pp. 387-395, 2008.

[4] Goodyear Dunlop Tires Germany GmbH, Technisches Handbuch LKW-/Busreifen, Company Publication, 2013.

[5] J. R. Beatty and B. J. Miksch, "A laboratory cutting and chipping tester for evaluating off-the-road and heavy-duty tire treads," Rubber Chemistry and Technology, vol. 55, no. 5, pp. 1531-1546, 1982.

[6] D. Manas, M. Manas, M. Staněk, and V. Pata, "Wear of tyre treads," Journal of Achievements in Materials and Manufacturing Engineering, vol. 37, no. 2, pp. 538-543, 2009.

[7] R. Stoček, G. Heinrich, M. Gehde, and A. Rauschenbach, "Investigations about notch length in pure-shear test specimen for exact analysis of crack propagation in elastomers," Journal of Plastics Technology, vol. 1, pp. 2-22, 2012.

[8] R. S. Rivlin and A. G. Thomas, "Rupture of rubber. I. Characteristic energy for tearing," Journal of Polymer Science, vol. 10, no. 3, pp. 291-318, 1953.

[9] P. Paris and F. Erdogan, "A critical analysis of crack propagation laws," Journal of Fluids Engineering, vol. 85, no. 4, pp. 528-533, 1963.

[10] A. N. Gent, P. B. Lindley, and A. G. Thomas, "Cut growth and fatigue of rubbers. I. The relationship between cut growth and fatigue," Journal of Applied Polymer Science, vol. 8, no. 1, pp. 455466, 1964. 
[11] K. A. Grosch, "Rubber abrasion and tire wear," Rubber Chemistry and Technology, vol. 81, no. 3, pp. 470-505, 2008.

[12] P. Ghosh, R. Stocek, M. Gehde, R. Mukhopadhyay, and R. Krishnakumar, "Investigation of fatigue crack growth characteristics of NR/BR blend based tyre tread compounds," International Journal of Fracture, vol. 188, no. 1, pp. 9-21, 2014.

[13] R. Stoček, G. Heinrich, M. Gehde, and R. Kipscholl, "Analysis of dynamic crack propagation in elastomers by simultaneous tensile- and pure-shear-mode testing," in Fracture Mechanics and Statistical Mechanics of Reinforced Elastomeric Blends, W. Grellmann, G. Heinrich, M. Kaliske, M. Klüppel, K. Schneider, and T. Vilgis, Eds., vol. 70 of Lecture Notes in Applied and Computational Mechanics, pp. 269-301, Springer, Berlin, Germany, 2013.

[14] R. Stoček, P. Ghosh, R. Mukhopadhyay, R. Kipscholl, and G. Heinrich, "Fracture behavior of rubber-like materials under classical fatigue crack growth vs. Chip \& cut analysis," in Proceedings of the 8th European Conference on Constitutive Models for Rubbers (ECCMR '13), pp. 323-328, June 2013. 

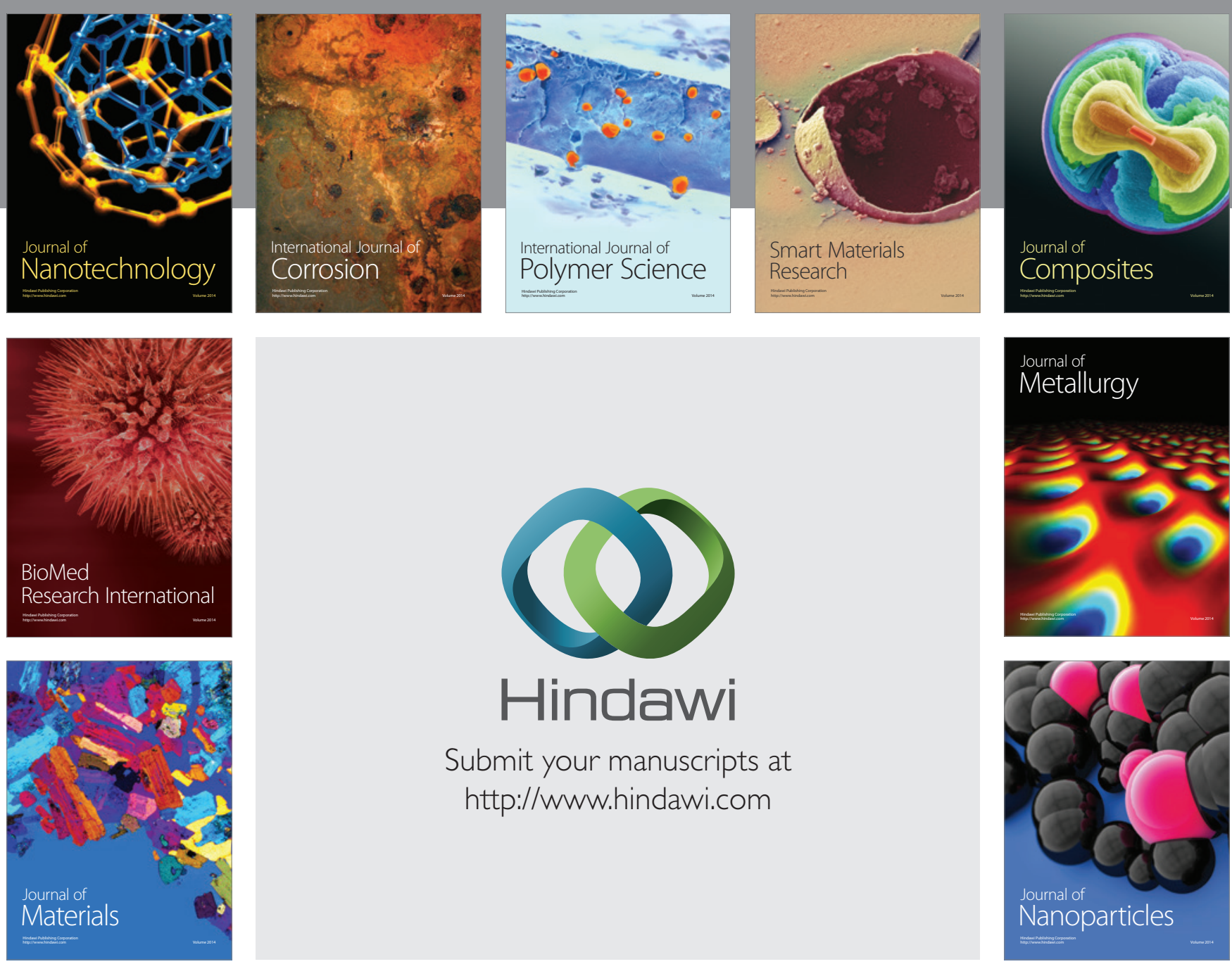

Submit your manuscripts at http://www.hindawi.com
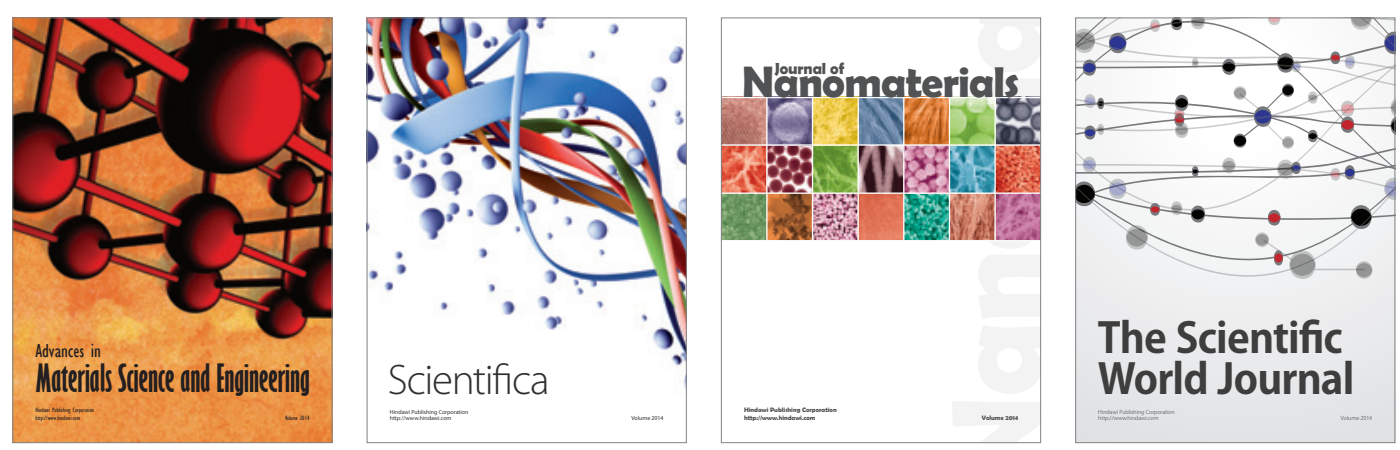

\section{The Scientific World Journal}
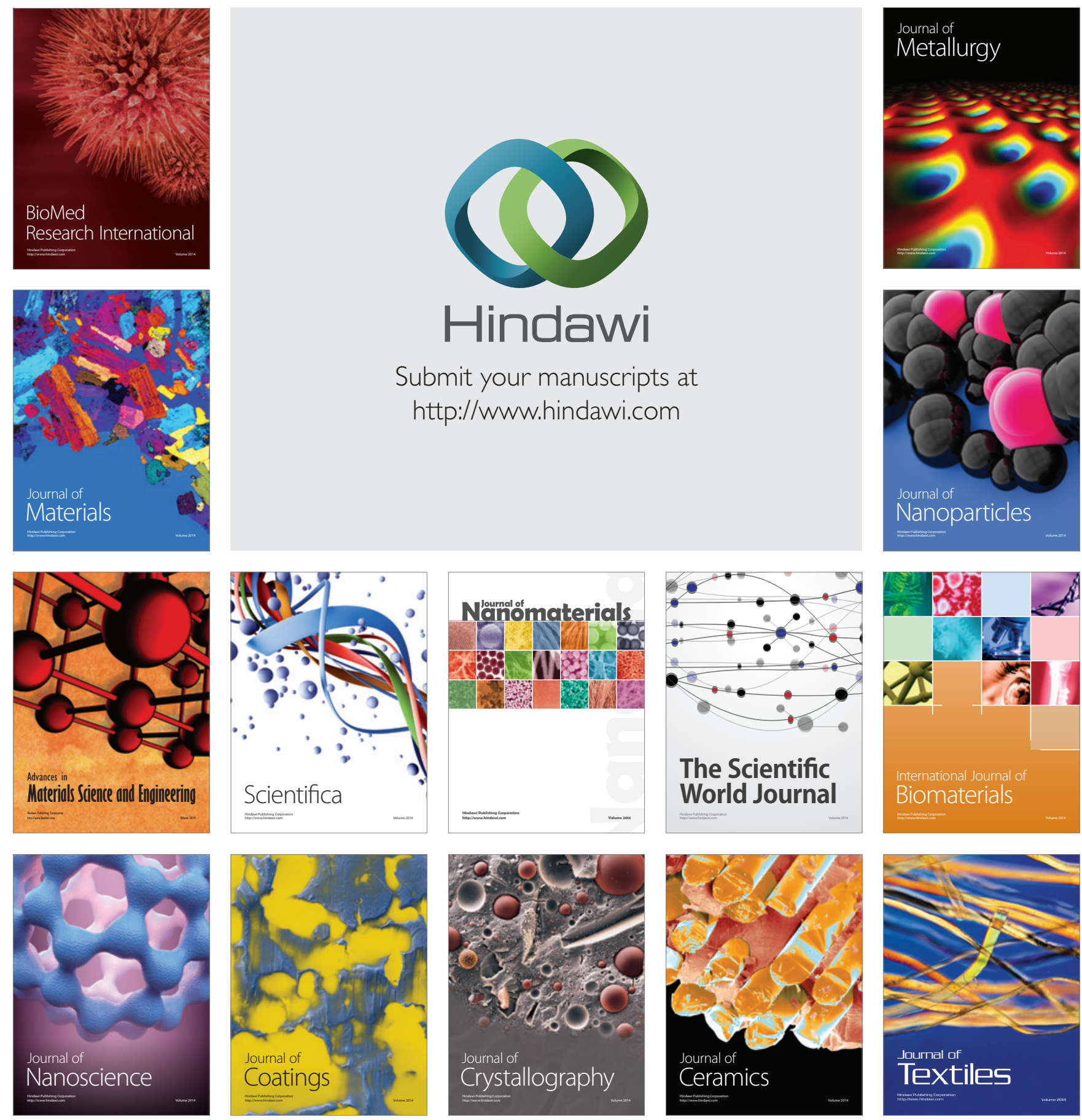